\title{
O experimento "curva de luz" do Laboratório Remoto de Física: uma proposta de atividade investigativa contextualizada epistemologicamente
}

The "light curve" experiment of the Physics Remote Laboratory: a proposal of an investigative activity epistemologically contextualized

\author{
Thiago Costa Caetano*1] \\ ${ }^{1}$ Universidade Federal de Itajubá, MG, Brasil.
}

Recebido em 5 de maio de 2021. Revisado em 18 de julho de 2021. Aceito em 3 de setembro de 2021.

\begin{abstract}
Neste trabalho apresentamos uma proposta de atividade experimental elaborada no contexto da disciplina Conceitos de Astronomia - AST929, do curso de licenciatura em Física da Universidade Federal de Itajubá. A principal ideia da proposta é utilizar o método de obtenção da relação período-luminosidade de estrelas variáveis Cefeidas como um elemento contextualizador. Um experimento controlado remotamente e um programa para a análise dos dados foram construídos especificamente para a atividade. Para ilustrar os procedimentos de coleta de dados e também a análise feita com o programa, realizamos um ensaio experimental no qual foram coletados dados de vinte objetos. As curvas de luz foram analisadas e obteve-se o período de pulsação e a magnitude absoluta média em cada caso. Os coeficientes da relação período-luminosidade foram obtidos através do método $\chi$-quadrado e os valores encontrados para os coeficientes foram $A=-2.822 \pm 0.035$ e $B=-1.410 \pm 0.016$. Esses valores concordam com a relação apresentada por Carrol \& Ostlie [1, a qual foi utilizada como base para a programação do experimento remoto. Isso demonstra que o experimento é consistente internamente e simula o comportamento de uma Cefeida de maneira adequada, do ponto de vista didático. O recurso mostrou-se profícuo, pois os estudantes coletam, em segundos, dados que levariam dias para serem coletados com observações reais. Os estudantes que participaram da atividade o fizeram durante o primeiro semestre do curso e portanto tiveram pouco contato com as ferramentas matemáticas do Ensino Superior. Apesar disso, a atividade pôde ser realizada sem dificuldades.
\end{abstract}

Palavras-chave: Ensino de Astronomia, Variáveis Cefeidas, Experimento Remoto.

In this paper we present a proposal of an experimental activity which was elaborated in the context of the subject Concepts of Astronomy - AST929, in the Physics undergraduate course of the Federal University of Itajubá. The main idea is to utilize the method of obtaining the period-luminosity relationship as a contextualizing element. A remotely controlled experiment and a software for data analysis have been developed specifically for this activity. To illustrate both data acquisition and analysis, we performed an experiment in which we have acquired data from twenty objects. The light curves were analyzed in order to obtain the period and the magnitude in each case. The coefficients were determined through the $\chi$-square method and the results we have found are $A=-2.822 \pm 0.035$ and $B=-1.410 \pm 0.016$, which are in agreement with those presented by Carrol \& Ostlie [1]. This tells us that the experiment has internal consistency and simulates the behavior of a cepheid variable star properly, from the didactical perspective. The resource has been shown to be beneficial as the students were able to acquire, in a few seconds, data that would take days, maybe weeks to acquire through real observations. Students who have participated in the activity were in the first semester of the undergraduate course, therefore they have had only little contact with the mathematical tools in higher education. Nonetheless, the activity was carried out without major difficulties.

Keywords: Astronomy Teaching, Cepheid, Remote Experiment.

\section{Introdução}

A partir do ano de 2012 ocorreram as primeiras iniciativas relacionadas ao Laboratório Remoto de Física $\mathbb{A}^{1}$ (ao qual iremos nos referir simplesmente como labremoto) na Universidade Federal de Itajubá (Unifei). Alguns anos depois, em 2015, foram inauguradas novas instalações

\footnotetext{
* Endereço de correspondência: tccaetano@unifei.edu.br

1 https://labremoto.unifei.edu.br
}

para Instituto de Física e Química (IFQ) da instituição e o laboratório ganhou um novo espaço. Isso possibilitou aumentar o seu acervo e teve como consequência uma melhoria significativa, tanto na sua estrutura como nos procedimentos e técnicas empregados no seu desenvolvimento. Atualmente, todos os experimentos do acervo podem ser acessados através da internet em qualquer momento do dia, de qualquer ponto do globo, o que torna o recurso particularmente interessante se considerarmos perspectivas como aquelas presentes nos trabalhos de 
Wang e Hannafin 2 e de Chia-Chen e Pei-Hsuan [3, que tratam de ambientes de aprendizagem melhorados por tecnologia, contextualizados e acessíveis independentemente do tempo ou do local. As referências [4 10. podem contribuir para que o leitor adquira uma visão mais ampla sobre esse tipo de recurso, bem como sobre as formas com que ele vem sendo empregado em diversos níveis e modalidades de ensino.

Por trás do desenvolvimento do laboratório, entre os seus pressupostos educacionais [11, está o fato de que as atividades experimentais são consideradas imprescindíveis no ensino 12,22 e apresentam grande potencial para familiarizar os estudantes com os métodos da ciência, levar ao desenvolvimento do raciocínio lógico, aumentar o potencial para análise de situações problema, facilitar a compreensão de conceitos abstratos e estabelecer relações entre o conteúdo teórico e algo mais concreto [23]. Apesar disso, essas atividades ainda são pouco empregadas dentro da sala de aula devido a diversos fatores, principalmente ligados à formação docente e à infraestrutura escolar 24].

Experimentos virtuais e a experimentação remota constituem alternativas para superação dos obstáculos comumente apontados pelos professores no ensino de ciências 25 31. Alternativas dessa natureza são particularmente interessantes pois consistem em recursos que podem ser acessados por meio da internet. De acordo com as Notas Estatísticas do Censo Escolar de 2020, dentre as escolas públicas de ensino médio, 79,3\% possuem computadores de mesa para os alunos e $80,4 \%$ delas possuem internet banda larga [32, o que tornaria possível, a princípio, o acesso a partir da escola. O recurso também poderia ser utilizado fora do espaço e do tempo escolar, dependendo do planejamento do docente e dos meios disponíveis para os estudantes. Tudo leva a crer que essa acessibilidade tende a se tornar cada vez melhor, haja visto as constantes melhorias que têm ocorrido nos meios de comunicação, na qualidade da conexão via internet e na conectividade através de dispositivos móveis, os quais têm se tornado cada vez mais populares.

Os experimentos controlados remotamente também representam uma boa alternativa para situações de periculosidade, como em experimentos que envolvem radioatividade, tensões elétricas elevadas ou ruído excessivo. Consideremos ainda certos fenômenos cujo estudo requer estrutura e treinamento específicos, sem mencionar que podem demandar muito tempo. O artifício da experimentação remota pode facilitar o estudo de tais fenômenos, como o caso que apresentamos neste trabalho. Descrevemos aqui uma proposta para a utilização do experimento "Curva de luz", que foi aplicada durante a disciplina "Conceitos de Astronomia - AST929", com estudantes ingressantes do curso de Licenciatura em Física da Unifei. Esses estudantes tiveram pouco contato com as ferramentas matemáticas do Ensino Superior, portanto foi desenvolvido um programa para auxiliá-los na análise das curvas de luz fornecidas pelo experimento, o qual também é descrito neste trabalho.

De forma sucinta, o "Curva de luz" permite obter medidas do fluxo de uma fonte luminosa que simula o comportamento de uma estrela do tipo Cefeida. Assim como os demais experimentos do labremoto, o "Curva de luz" tem a característica de ser propício à atividades investigativas [33, 34] e isso está atribuído a alguns fatores como, por exemplo:

(a) normalmente as medidas são realizadas em instrumentos reais - analógicos, na maior parte das vezes - através das imagens mostradas pelas câmeras. Portanto, o usuário precisa familiarizarse com a precisão, faixa de operação, fontes de erros, procedimentos de medidas, entre outros, exatamente como faria um cientista em seu laboratório;

(b) ausência de roteiros predefinidos, o que leva o usuário a refletir sobre o procedimento experimental que irá utilizar. Para isso é preciso colocar todo o processo em perspectiva, analisar o problema e as hipóteses, então planejar adequadamente o procedimento experimental;

(c) existência de diversas câmeras nos experimentos, permitindo assim que o usuário tenha acesso a diversos pontos de vista sobre os acontecimentos na bancada. Sensores também contribuem para que o usuário tenha leitura de grandezas físicas que não são visíveis, como temperatura, corrente e campo magnético.

Este trabalho está organizado da seguinte maneira: (1) inicialmente é feita uma descrição detalhada do conjunto experimental "Curva de luz", abordando aspectos da construção do hardware, a fundamentação teórica por trás do trabalho computacional e aspectos da interface web do experimento; (2) então, é feita a descrição do procedimento de aquisição de dados, onde aproveitamos para apresentar o software que foi desenvolvido especificamente para utilização com o "Curva de luz" e os princípios da análise estatística realizada por ele. Na mesma seção discutimos o procedimento de aquisição de dados segundo uma perspectiva contextualizadora, que leva em consideração aspectos epistemológicos; (3) em seguida passamos para a análise dos dados coletados, onde é feita a obtenção da relação período-luminosidade; e (4) finalmente, fazemos algumas considerações à respeito do experimento e da proposta que é apresentada.

\section{O Experimento "Curva de luz"}

O experimento é parte do acervo do labremoto e consiste em uma lâmpada incandescente cuja luminosidade é controlada por um circuito. O conjunto é mantido dentro de uma caixa escura juntamente com uma câmera que permite ao usuário observar o que acontece no seu 
interior. Há também um sensor de luminosidade, um LDR (Light-Dependent Resistor), conectado ao circuito e que está fixado na parte superior da caixa, logo acima da lâmpada. Tanto a câmera quanto o circuito estão conectados a um computador/servidor que executa dois algoritmos que realizam a aquisição de imagens da câmera e a comunicação com o circuito. Esses algoritmos respondem a uma interface web através da qual o usuário controla o experimento. ${ }^{2}$

Quando o usuário liga a lâmpada, esta começa a pulsar de tal forma que a variação do brilho simula o comportamento típico de estrelas variáveis do tipo Cefeida. O período de pulsação pode ser definido pelo usuário através da interface ou pode-se gerar um período aleatoriamente, o que é particularmente útil em atividades investigativas. A lâmpada pode ser observada em tempo real através da câmera e o sensor de luminosidade permite que sejam feitas medidas do fluxo luminoso. A quantidade de medidas por segundo e o tempo de duração da coleta de dados são parâmetros que podem ser definidos pelo usuário. Ao final da coleta, os dados são inseridos em uma tabela na interface e também podem ser baixados como um arquivo ASCII (arquivo do bloco de notas). Isso é conveniente, caso se deseje utilizar os dados em um programa para construção de gráficos, por exemplo.

As seções seguintes fornecem mais detalhes sobre o experimento, sobre sua construção, funcionamento e sobre cada um dos componentes que foram mencionados.

\subsection{Construção do experimento}

Nos projetos que são desenvolvidos no labremoto, sempre que um módulo Arduino ou um microcontrolador ATMega328, ou qualquer outro componente delicado dessa natureza é utilizado em um circuito, tem-se empregado um regulador de tensão na entrada, entre a fonte de alimentação e o circuito. Essa prática já provou ser útil mais de uma vez e é altamente recomendável, sobretudo se a fonte que estiver sendo utilizada não for de boa qualidade ou a rede elétrica do local apresentar instabilidades. Também apresenta a vantagem de possibilitar que a fonte seja substituída por outra de tensão nominal diferente, sem que seja necessário alterar o projeto do circuito.

A Figura 1 mostra o esquema de montagem dessa parte do circuito. A fonte foi ajustada para 9 volts e 2 amperes ${ }^{3} \mathrm{O}$ valor da corrente não é mostrado no visor da fonte da Figura 1 pois não há corrente no circuito.

\footnotetext{
2 https://labremoto.unifei.edu.br/src/curva-de-luz.php

3 Testes indicaram que a tensão de alimentação do L7805 deve ser de pelo menos $7 \mathrm{~V}$ para que a tensão fornecida por ele seja estável. O componente admite até $18 \mathrm{~V}$ em sua entrada, porém valores mais elevados geram mais dissipação de calor. Assim, optamos por um valor intermediário, de $9 \mathrm{~V}$. Já no que diz respeito à corrente, esta deve ser suficiente para fornecer a potência que o circuito necessita. Escolhemos 2 amperes, que é mais que o bastante. Mas apenas a corrente necessária é consumida.
}

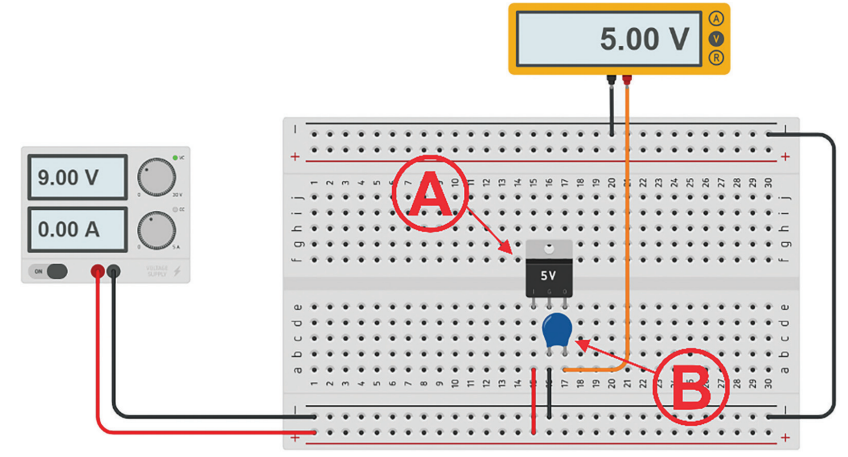

Figura 1: Esquema de montagem do regulador de tensão para o experimento "Curva de luz". Foi utilizado um L7805 (item A) e a fonte de alimentação foi ajustada para 9.00 volts e 2.00 amperes (SI). O capacitor mostrado na figura (item B) é um capacitor cerâmico de 100 nF e sua função é melhorar a resposta transiente do sistema. Um multímetro (não faz parte do circuito) foi inserido na figura apenas para mostrar a tensão de saída: 5,00 volts. A figura foi elaborada com auxílio da plataforma TinkerCAD.

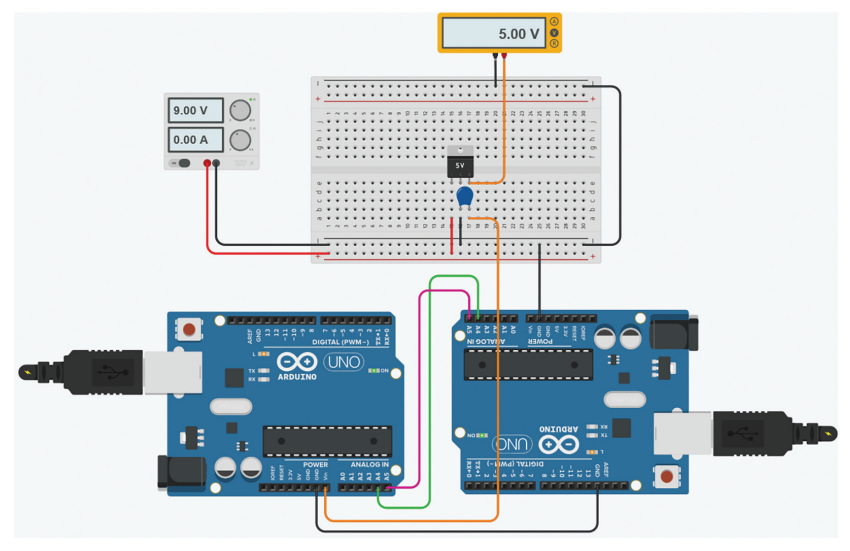

Figura 2: Circuito contendo o regulador de tensão mostrado na Figura 1]e duas placas do tipo Arduino UNO que se comunicam utilizando o protocolo $\mathrm{I}^{2} \mathrm{C}$. A placa da direita está configurada no modo master e é alimentada pelo cabo USB conectado ao computador. A placa da esquerda está configurada no modo slave e é alimentada pelo L7805.

O componente L7805 fornece 5,00 volts e até 1 ampere e é utilizado para alimentar uma das placas Arduino do circuito, um relê e o módulo PIC MC-8A (ao qual iremos nos referir como PIC deste ponto em diante).

O circuito contém duas placas Arduino que se comunicam através do protocolo $\mathrm{I}^{2} \mathrm{C}$ (Inter-Integrated Circuit) ${ }^{4}$ Para que isso seja possível, as portas analógicas A4 e A5 - dados (SDA) e clock (SCL), respectivamente de ambas as placas devem estar conectadas, conforme indicado na Figura 2, Além disso, ambas as placas devem ter o mesmo nível de tensão em GND (ground), motivo pelo qual é necessária uma conexão entre essas portas de ambas as placas.

\footnotetext{
4 https://learn.sparkfun.com/tutorials/i2c/all
} 


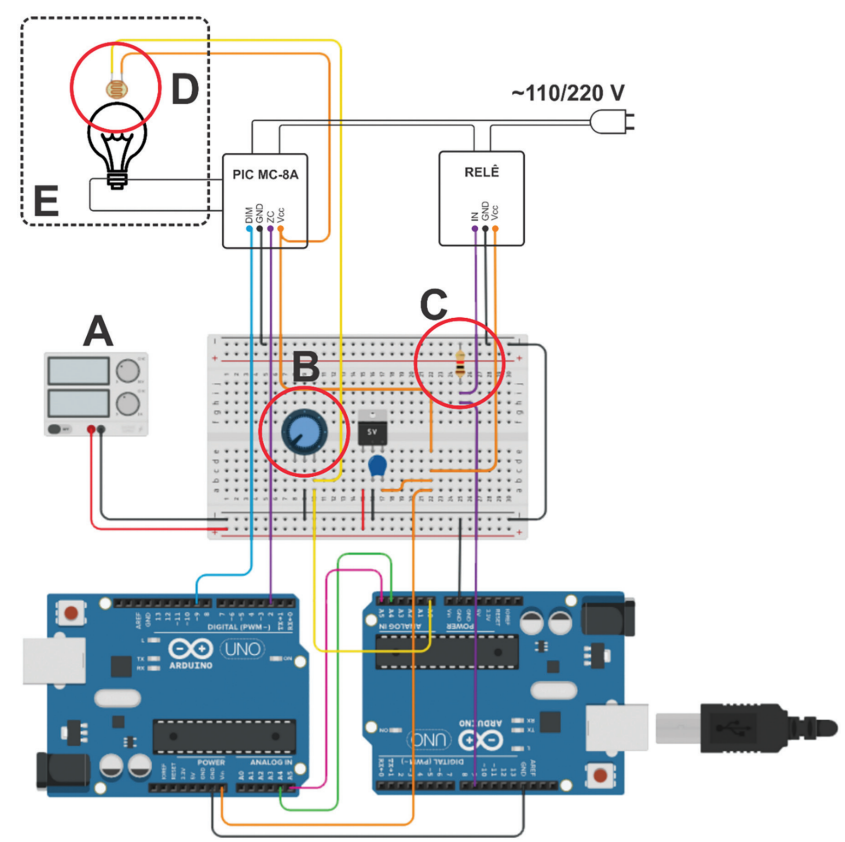

Figura 3: Diagrama da montagem completa do experimento "Curva de luz". O item A é uma fonte de alimentação de corrente contínua, ajustada para 9,00 volts e 2 amperes. O item B é um potenciômetro de $10 \mathrm{k} \Omega$ que permite calibrar a sensibilidade do sensor LDR em D. O item C é um resistor pull-down, conectado ao terminal IN do relê de acionamento da lâmpada. O Arduino mostrado à direita é o master e o da esquerda é o slave. A região $\mathrm{E}$ da linha tracejada representa os itens que estão mantidos no interior da caixa escura.

Entre as razões mais frequentes pelas quais múltiplas placas são empregadas em um projeto, está a necessidade de aumentar a quantidade de portas disponíveis, ou simplesmente de melhorar a eficiência por meio do gerenciamento de tarefas entre múltiplos núcleos de processamento. Neste projeto, em particular, a utilização de duas placas foi necessária porque a execução do código sofre interrupções externas, o que pode ocasionar atraso na execução de outras rotinas, entre elas, aquelas ligadas à comunicação com a interface do experimento. Esse aspecto ficará mais claro nas seções seguintes, onde se discute o aspecto computacional.

O acionamento da lâmpada é feito por um relê. ${ }^{5}$ Esse componente é alimentado pelo L7805 com uma tensão de 5 volts e consome aproximadamente $100 \mathrm{~mA}$ de corrente (contínua) quando está acionado. O sinal para fechamento/abertura do relê é emitido pela porta digital 9 da placa master (placa Arduino da direita na Figura 3. Um resistor pull-down de $10 \mathrm{k} \Omega$ (item $\mathrm{C}$ da Figura 3 foi empregado para garantir a estabilidade do sinal no terminal IN do relê e evitar que sinais espúrios provoquem o acionamento/desacionamento indesejado do componente.

\footnotetext{
5 Tensão de acionamento de $5 \mathrm{~V}$ e corrente máxima de $10 \mathrm{~A}$ quando ligado em $110 \mathrm{~V}, 20 \mathrm{~A}$ para $220 \mathrm{~V}$.
}

O módulo PIC pode ser considerado o elemento central deste projeto. Além de realizar o controle da potência que é fornecida para a lâmpada, também pode ser empregado como uma espécie de cronômetro. Essa característica é particularmente importante, portanto, vejamos melhor como isso funciona.

A tensão elétrica fornecida através da rede doméstica, das tomadas em nossas residências, é dita alternada. Significa que o sinal da tensão se inverte, ora é positivo, ora é negativo, e a frequência do sinal é de $60 \mathrm{~Hz}$. Se medíssemos o comportamento da tensão ao longo do tempo teríamos um gráfico sinusoidal e veríamos que a curva do gráfico passa pelo zero - valor nulo para a tensão - 120 vezes a cada segundo. O PIC detecta essa passagem e envia um sinal através do seu terminal ZC zero cross - para a porta 2 da placa slave (ver Figura 3 ) sempre que ocorre a passagem pelo zero. $\mathrm{O}$ sinal dispara a execução de uma função específica (descrita na seção seguinte), que utiliza a frequência da passagem pelo zero para medir a passagem do tempo. Ou seja, toda vez que a função é executada, sabe-se que se passaram 8,33 milissegundos desde a sua última execução, permitindo que o PIC seja utilizado como um cronômetro.

O PIC é alimentado pelo L7805 e o seu terminal DIM (Figura 3) está conectado à porta digital 9 da placa slave, por onde é emitido o sinal que controla a potência da lâmpada. Os terminais da rede - 110 ou $220 \mathrm{~V}-$ e os terminais da lâmpada também estão conectados ao PIC e a lâmpada é mantida no interior de uma caixa escura para, em primeiro lugar, evitar a contaminação das medidas por fontes externas e, em segundo lugar, para que não interfira nos demais experimentos e atividades do labremoto.

No interior da caixa foi colocado um LDR, que funciona como um sensor de fluxo luminoso. A resistência do componente depende da quantidade de luz que incide em sua superfície. Portanto, conectando-o em série com um resistor convencional é possível medir a diferença de potencial em seus terminais e obter a luminosidade. A calibração do sensor é feita ajustando-se o valor do segundo resistor e por isso utilizamos um potenciômetro de $10 \mathrm{k} \Omega$ em série com o LDR (ver Figura 3 ).

\subsection{Fundamentos computacionais}

O trabalho computacional é bastante abrangente, incluindo desde o código desenvolvido para os microcontroladores até a interface web, que representa o painel de controle do experimento. Através dele o usuário pode observar o fenômeno em tempo real e controlar um determinado número de parâmetros. Toda a estrutura de comunicação entre esses elementos e o seu funcionamento são apresentados em [11]. Iremos nos concentrar aqui nos detalhes dos códigos que foram desenvolvidos para os microcontroladores - placas Arduino - e alguns aspectos da interface web, aqueles pertinentes à compreensão do funcionamento deste experimento em particular. 


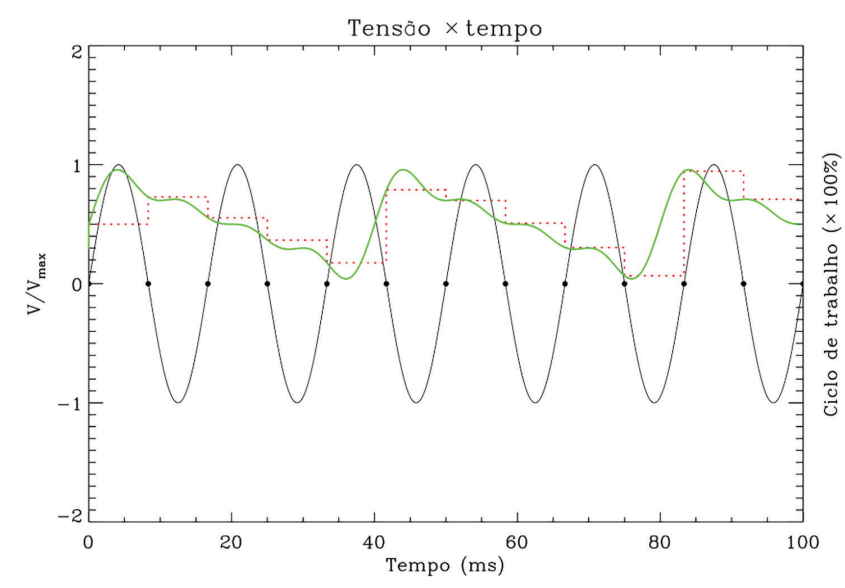

Figura 4: Gráfico da tensão em função do tempo. A linha contínua preta indica o comportamento da tensão elétrica alternada da rede do laboratório. Os valores, em volts, foram normalizados e estão expressos no intervalo $[-1.0 ; 1.0]$. Os pontos pretos indicam as passagens pelo zero. A linha tracejada vermelha representa os valores calculados para o ciclo de trabalho da lâmpada entre duas passagens sucessivas pelo zero e a linha sólida verde representa a função da Equação (1) com $k$ igual a 4 . O gráfico corresponde a um caso particular em que o período de oscilação da lâmpada é de $40 \mathrm{~ms}$.

Como mencionado anteriormente, o "Curva de luz" conta com duas placas Arduino em seu circuito, uma configurada para operar no modo slave, e outra no modo master. A principal função da placa slave é o controle da potência da lâmpada, a qual deve oscilar periodicamente segundo um intervalo de tempo definido pelo usuário. A linha verde no gráfico da Figura 4 mostra o comportamento teórico (desejado) da potência da lâmpada em função do tempo, considerando-se um caso particular em que o período de oscilação é de 40 milissegundos (a potência em cada instante é dada pela Equação (1)). Na prática, não é possível selecionar intervalos tão pequenos, porém, à guisa de ilustração, adotamos o valor de $40 \mathrm{~ms}$ para permitir que o leitor realize comparações mais imediatas através dos gráficos da Figura 4 e da Figura 5

O ciclo de trabalho é calculado a partir do valor da potência no instante da passagem pelo zero e está representado pela linha vermelha tracejada. Uma vez que o seu valor não pode ser alterado no intervalo entre duas passagens consecutivas pelo zero, resulta que o gráfico para o ciclo de trabalho não é uma função contínua.

O ciclo de trabalho de um componente é a razão entre o tempo em que este componente permanece ativo, em estado de trabalho, pelo tempo total do ciclo. Considere, por exemplo, uma lâmpada que permanece acesa por 10 segundos e então apagada por 90 segundos; e que isso se repita a cada ciclo. O tempo total é de 100 segundos e a lâmpada apresenta, portanto, um ciclo de trabalho de $10 \%$ apenas. Imagine agora que temos 120 repetições

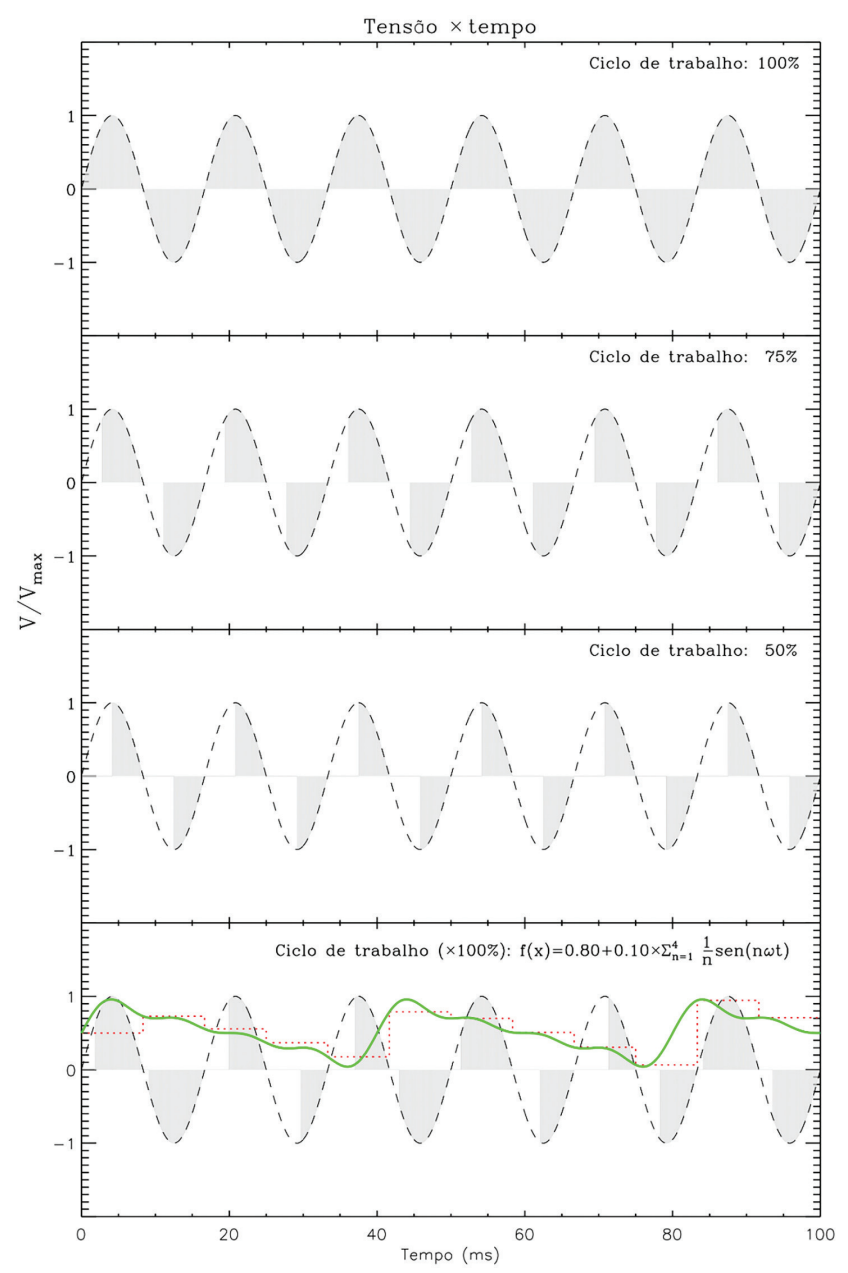

Figura 5: Gráficos da tensão por tempo semelhantes ao da $\mathrm{Fi}$ gura 4. As áreas sombreadas representam os intervalos de tempo em que há passagem de corrente pelo circuito. Diferentes valores para o ciclo de trabalho foram considerados. A linha contínua verde considera um período de oscilação de 40 milissegundos.

(ciclos) em um segundo, que equivale a quantidade de semiciclos da nossa rede doméstica. Se é desejado que a lâmpada funcione com $50 \%$ da sua potência máxima, basta fazer com que seu ciclo de trabalho seja de $50 \%$ em cada um dos semiciclos. Nesse caso, o circuito permanece aberto - sem passagem de corrente - metade do tempo de um semiciclo e fechado durante a outra metade.

A Figura 5 mostra alguns gráficos da tensão da rede em função do tempo (os valores da tensão estão normalizados). As áreas sombreadas representam o intervalo de tempo em que a lâmpada se encontra ativa, considerando diferentes valores para o ciclo de trabalho. Os três primeiros gráficos da figura, de cima para baixo, consideram valores constantes, respectivamente, 100, 75 e 50 porcento. O último gráfico apresenta o comportamento do ciclo de trabalho para um caso particular em que a potência - linha contínua verde - oscila com um período de 40 milissegundos, semelhante ao caso da Figura 4 Adotamos aqui uma definição para o ciclo de trabalho 
mais precisa, um pouco diferente daquela que foi dada anteriormente como exemplo. Consideramos que o ciclo de trabalho é equivalente à razão entre a área do gráfico no intervalo em que o componente se encontra ativo pela área do gráfico no intervalo total do semiciclo. Dito de outra forma, em cada semiciclo, o ciclo de trabalho equivale à razão entre a área sombreada e a área total do semiciclo.

A função adotada para descrever o comportamento da potência da lâmpada é uma variação de funções tipicamente empregadas em ajustes com curvas de luz de estrelas variáveis Cefeidas clássicas [35 37. Tendo em consideração os objetivos pedagógicos do experimento em questão, entretanto, optou-se por uma versão simplificada $(k=4)$ das equações, mas que é adequada tanto para produzir uma simulação verossímil do fenômeno, quanto permitir ter uma noção das técnicas que são aplicadas nos ajustes. Valores mais elevados para o coeficiente $k$ tornariam a análise das curvas de luz ainda mais complexa e isso inviabilizaria a sua execução no momento do curso em que os estudantes se encontram. Por outro lado, valores menores são insuficientes para produzirem uma simulação adequada do fenômeno.

Seja $P_{L}$ o período de oscilação da lâmpada, definido pelo usuário. Então a potência $W$ em cada instante é dada pela função

$$
W(t)=A+B \sum_{n=1}^{k} \frac{1}{n} \operatorname{sen}\left(n \omega_{L} t\right)
$$

em que a frequência angular $\omega_{L}$ equivale a $2 \pi P_{L}^{-1}$. O parâmetro $B$ da equação tem relação com a amplitude da onda e $A$, com o seu deslocamento ao longo do eixo y. Esses parâmetros são úteis para controlar alguns aspectos da onda, como o valor mínimo da potência, por exemplo. $\mathrm{O}$ valor adotado para $A$ foi de 0.80 e adotou-se 0.10 para o parâmetro $B$. Os valores são escolhidos de forma empírica e iterativa, até que o gráfico resultante apresente as características desejadas. Por último, como mencionado, no experimento e na atividade em questão, adotamos $k$ igual a 4 por razões didáticas.

Dado um valor para a potência $W$, o ciclo de trabalho correspondente é executado fazendo-se com que o circuito fique aberto durante parte do semiciclo e então se torne fechado, permitindo a passagem da corrente. Conforme a definição que adotamos para o ciclo de trabalho, o tempo que o circuito deve permanecer aberto é medido sempre a partir da passagem pelo zero e é fornecido pela expressão

$$
\mathrm{t}_{\mathrm{T}}-\mathrm{t}_{\mathrm{ZC}}=\frac{1}{\omega_{\mathrm{R}}} \cos ^{-1}(2 \mathrm{~W}-1)
$$

obtida a partir do cálculo da razão entre áreas. O termo $t_{T}-t_{\mathrm{ZC}}$ é o tempo de permanência no estado aberto (componente inativo) medido a partir da última passagem pelo zero. A constante $\omega_{R}$ é a frequência angular da rede.
Na prática, o funcionamento segue os passos seguintes:

1. O PIC detecta a passagem pelo zero e envia um sinal até a porta 2 da placa slave;

2. O sinal da porta 2 dispara a execução de uma função que: (a) incrementa a contagem do tempo em $8333 \mu$ s (duração do semiciclo da rede); (b) calcula a potência da lâmpada (Eq. 1) segundo o período $P_{L}$ definido pelo usuário; (c) calcula o ciclo de trabalho (equivalente a potência relativa, isto é $\left.P / P_{\max }\right)$ e (d) calcula o tempo $\mathrm{t}_{T}-\mathrm{t}_{\mathrm{ZC}}$ (Eq. 2);

3. No instante $t_{T}-t_{\mathrm{ZC}}$, a partir do evento do item 1 , a placa slave envia um pulso com duração de $10 \mu \mathrm{s}$ para o terminal DIM do PIC, que fecha o circuito e dá início ao ciclo de trabalho 6

4. O circuito permanece fechado até a próxima passagem pelo zero, momento em que ele é automaticamente interrompido pelo PIC. Reitera-se então os passos de 1 a 4 .

A função delayMicroseconds é utilizada no passo 3 para fazer com que o código aguarde o instante exato do fechamento do circuito. Essa função interrompe a execução do código e, como se pode inferir, é executada com uma frequência de $120 \mathrm{~Hz}$. Nos casos em que o ciclo de trabalho assume valores pequenos, menores que $41 \%$ por exemplo, a execução do código sofre interrupções significativas que podem comprometer o tempo de processamento de outras funções e aumentar, dessa forma, o tempo de resposta. Essa é precisamente a razão pela qual o controle de potência foi delegado a um processador secundário. Dessa forma as funções na placa master não sofrem interrupções e a comunicação do experimento com a interface não é prejudicada.

Do ponto de vista teórico, pode-se dizer que o código desenvolvido para a master é mais simples e sua estrutura se parece muito com a dos códigos de outros experimentos do labremoto. Uma das suas principais funções já deve estar clara para o leitor nesse ponto, que é a comunicação com a placa slave. Ela é feita exclusivamente para que seja possível fornecer o valor do período de oscilação da lâmpada, o qual é definido pelo usuário através da interface web e repassado à placa slave pela master. Outra função muito importante é a comunicação com o servidor, uma comunicação serial.

O servidor RESTful - que segue a arquitetura REST, de Representational State Transfer - está conectado à master e à rede internet, de forma que ele pode enviar e receber comandos de maneira bilateral. Os comandos da interface que chegam até a master são interpretados e as ações correspondentes são executadas.

\footnotetext{
6 A duração do pulso deve ser desprezível quando comparada à duração total do semiciclo. Dessa forma, sua influência nos valores calculados para a potência e para o ciclo de trabalho será inexpressiva. Valores muito pequenos, em contrapartida, podem não ser suficientes para o funcionamento adequado do PIC. Recomenda-se que esse valor seja determinado por meio de testes, como foi o caso deste trabalho.
} 


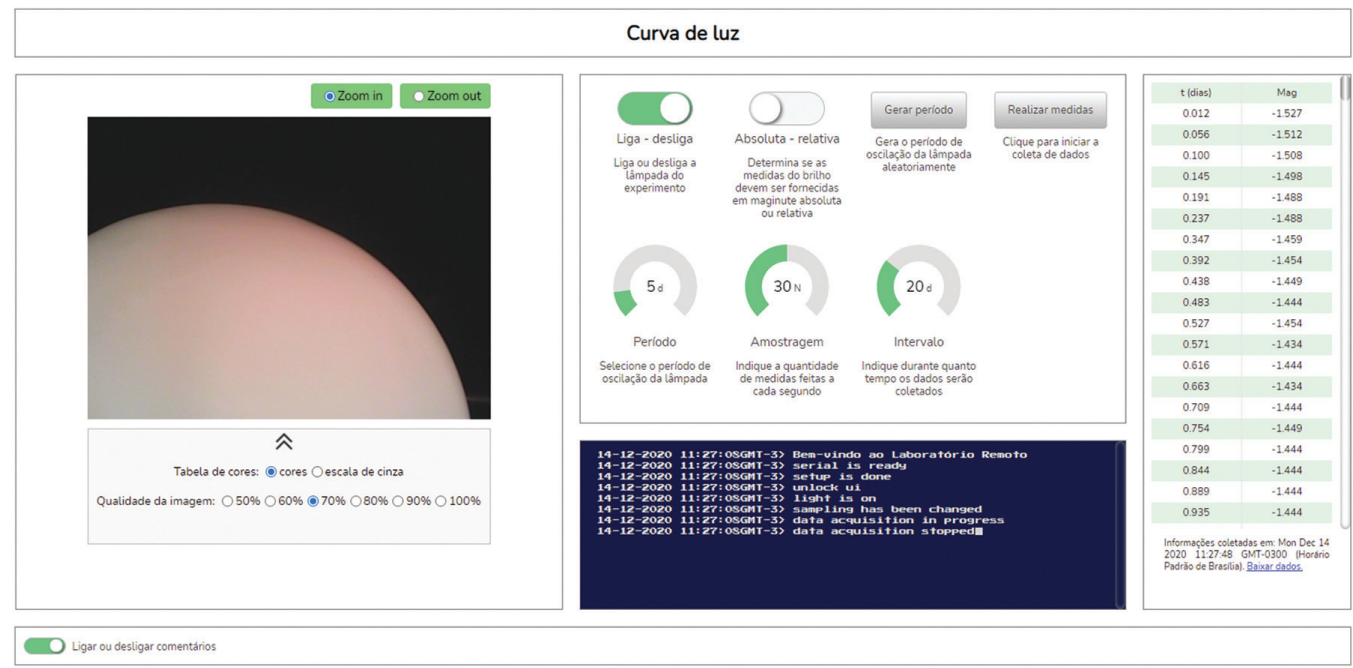

Figura 6: Interface do experimento "Curva de luz", disponível através do endereço https://labremoto.unifei.edu.br/src/curva-de -luz.php

No início da execução, um comando é enviado de volta à interface para indicar ao usuário que seu comando foi recebido e a ação está em execução. Chamamos isso de acknowledgment do experimento. Caso esse comando não seja recebido dentro de certo período de tempo, digamos três segundos, a ação correspondente do usuário na interface é automaticamente revertida e o usuário é informado da ausência de resposta do experimento. Mas se há resposta e a ação é executada normalmente, ao ser concluída, outro comando é enviado para a interface para informar o usuário que a ação solicitada terminou.

As ações que podem ser executadas no experimento "Curva de luz" são:

a. Alterar o valor do período de oscilação da lâmpada para um valor definido;

b. Modificar o tamanho da amostra para a coleta de dados;

c. Ligar e desligar a lâmpada;

d. Realizar as medidas;

e. Definir aleatoriamente o período de oscilação da lâmpada;

f. Selecionar entre magnitude absoluta e magnitude relativa para os valores de saída.

Os códigos desenvolvidos tanto para a master quanto para a slave estão disponíveis no site do labremoto 7 na seção "Curva de luz".

\subsection{Interface do experimento}

A Figura 6 mostra a interface do experimento "Curva de luz". Alguns elementos são comuns a todos os experimentos do laboratório. A área do vídeo é mostrada à esquerda. O streaming das imagens é feito diretamente

\footnotetext{
7 https://labremoto.unifei.edu.br/src/materiais.php
}

para esse quadro e o usuário tem algumas opções disponíveis: zoom in e zoom out, que permitem ampliar ou reduzir áreas específicas da imagem. Para isso, basta selecionar a opção desejada e clicar sobre o ponto que se deseja ampliar ou reduzir.

Embaixo da imagem há um painel retrátil que contém algumas configurações de cores e qualidade. Essas opções são úteis dependendo da velocidade da internet do usuário. Imagens em escala de cinza e com menor qualidade exigem menos da conexão e, por consequência, contribuem para reduzir a latência na transferência das imagens. No caso do "Curva de luz" há apenas uma webcam disponível e não há, portanto, um seletor para as câmeras na interface. Contudo, é interessante mencionar que esse recurso está disponível em experimentos com mais de uma câmera, pois trata-se de uma técnica que foi desenvolvida no labremoto e permite que seja feito o streaming da imagem de webcams convencionais, conectadas às portas USB do computador. Isso contribui para que os projetos de experimentos remotos no laboratório tornem-se mais práticos e muito mais baratos, visto que há uma infinidade de modelos de webcams USB disponíveis para todos os sistemas operacionais cujo custo é consideravelmente menor que as denominadas câmeras IP. O fato da técnica em questão também permitir que se permute a câmera sem a necessidade de recarregar a página ou qualquer interação com o servidor melhora a navegabilidade, a experiência do usuário, torna a interação com o experimento mais rica e eleva o seu potencial didático-pedagógico. Observar um experimento é apenas uma parte do processo experimental. Observá-lo de um único ponto de vista é uma parte ainda menor. É preciso ter controle dos parâmetros do experimento e poder realizar medidas, coletar dados, ter acesso a outras perspectivas, ter leitura clara de instrumentos na bancada, conhecer o processo por trás daquilo que é mostrado através de uma interface. Sugerimos aos 
Quadro 1: Controles disponíveis no painel de controle da interface web do "Curva de luz".

\begin{tabular}{|c|c|c|c|}
\hline & Tipo & Título & Ação \\
\hline 1 & Switch & Liga/desliga & Liga ou desliga a lâmpada do experimento. \\
\hline 2 & Switch & Absoluta/relativa & $\begin{array}{l}\text { Define se as medidas feitas devem ser fornecidas em termos da magnitude } \\
\text { absoluta ou da magnitude aparente da fonte. }\end{array}$ \\
\hline 3 & Botão & Gerar período & Escolhe um valor aleatório para o período de oscilação da lâmpada. \\
\hline 4 & Botão & Realizar medidas & $\begin{array}{l}\text { Inicia a coleta de dados. São feitas } \mathbf{N} \text { medidas por unidade de tempo durante } \\
\text { um intervalo de tempo } \mathbf{T} \text {. O valor de } \mathbf{N} \text { é determinado pelo controle da linha } 5 \\
\text { e o tempo } \mathbf{T} \text { é determinado pelo controle da linha } 6 \text { deste quadro. }\end{array}$ \\
\hline 5 & Knob & Período & $\begin{array}{l}\text { Determina um período, em dias*, para a oscilação da lâmpada. São permitidos } \\
\text { valores inteiros no intervalo de } 1 \text { a } 30 \text { dias*. }\end{array}$ \\
\hline 6 & Knob & Amostragem & $\begin{array}{l}\text { Determina a quantidade } \mathbf{N} \text { de medidas que devem ser realizadas por unidade } \\
\text { de tempo. Os valores disponíveis são número inteiros no intervalo }[10 ; 50] \text {. }\end{array}$ \\
\hline 7 & Knob & Intervalo & $\begin{array}{l}\text { Determina a duração } \mathbf{T} \text {, em dias*, da coleta de dados. Os valores permitidos } \\
\text { são números inteiros no intervalo }[2 ; 60] .\end{array}$ \\
\hline
\end{tabular}

*O experimento emprega um fator de escala para o tempo em que 1 dia corresponde a 1 segundo em nossa escala de tempo.
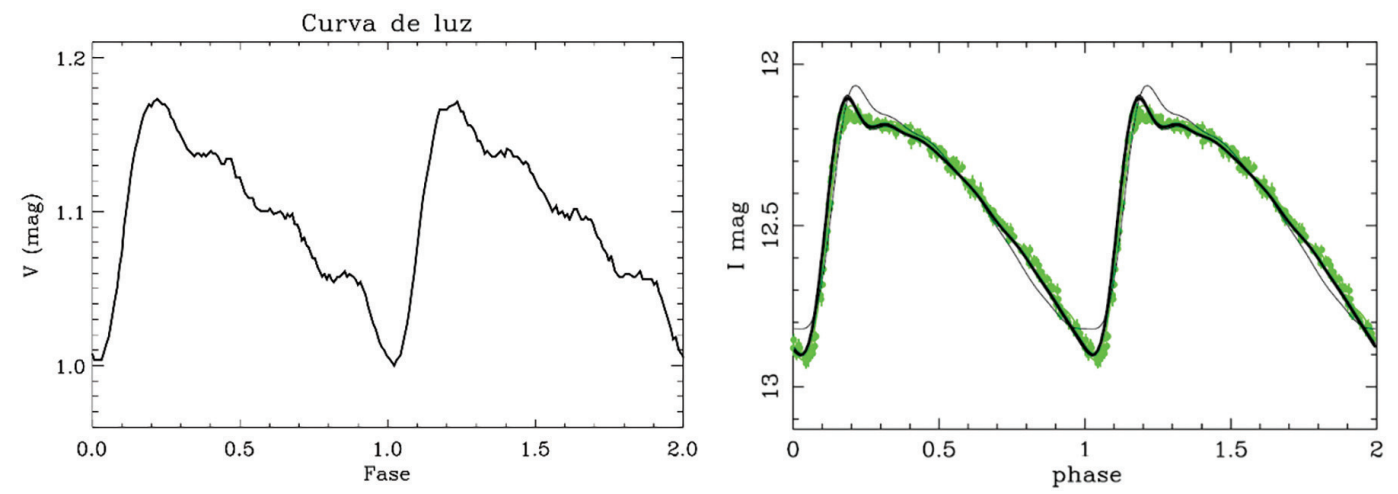

Figura 7: À esquerda - gráfico construído com dados coletados através do experimento "Curva de luz". Foram feitas 50 medidas por unidade de tempo durante um intervalo de 16 "dias" e o período da oscilação da fonte é de 4 "dias". À direita - gráfico do comportamento da magnitude medida na banda I para uma estrela Cefeida clássica da Grande Nuvem de Magalhães [35].

leitores que consultem os pressupostos pedagógicos do labremoto em [11].

No quadro central da Figura 6 há dois elementos: o log e o painel de controle. O log é o elemento mais abaixo e está presente na interface de todos os experimentos do labremoto. Nele o usuário pode ler os comandos que chegam ou que são enviados para o experimento, e a hora em que isso ocorreu. Desse modo o usuário pode ter ideia se tudo está correndo bem na comunicação ou se ocorreram falhas no processo. Acima temos o painel de controle, que é específico para cada experimento. Seus elementos são descritos em detalhes no Quadro 1.

Os valores coletados no experimento são inseridos em uma tabela no quadro à direita da Figura 6 , e podem ser baixados através de um link que é disponibilizado na parte inferior desse quadro, sempre após o término da coleta. O arquivo fornecido para download é um arquivo de texto comum - plain text - que pode ser importado para qualquer programa de construção de gráficos ou simplesmente copiado para este sem que haja problemas de codificação.

A Figura 7- gráfico à esquerda - contém um exemplo de gráfico construído com esses dados. Foram feitas 50 medidas por unidade de tempo durante 16 "dias" e o período de oscilação da fonte foi de 4 "dias" 8 Na mesma figura, à direita, é mostrado um gráfico do comportamento da magnitude na banda I de uma estrela variável Cefeida clássica localizada na Grande Nuvem de Magalhães 35. Em ambos os casos são mostrados dados referentes a duas oscilações das respectivas fontes. É possível perceber a semelhança que existe quanto ao comportamento da fonte nos dois casos e, portanto, consideramos que o experimento está adequado tanto do ponto de vista teórico quanto sob a óptica didáticopedagógica.

\footnotetext{
${ }_{8}$ Os dados estão disponíveis em https://labremoto.unifei.edu.br/ materials/lightCurve/dados.txt
} 

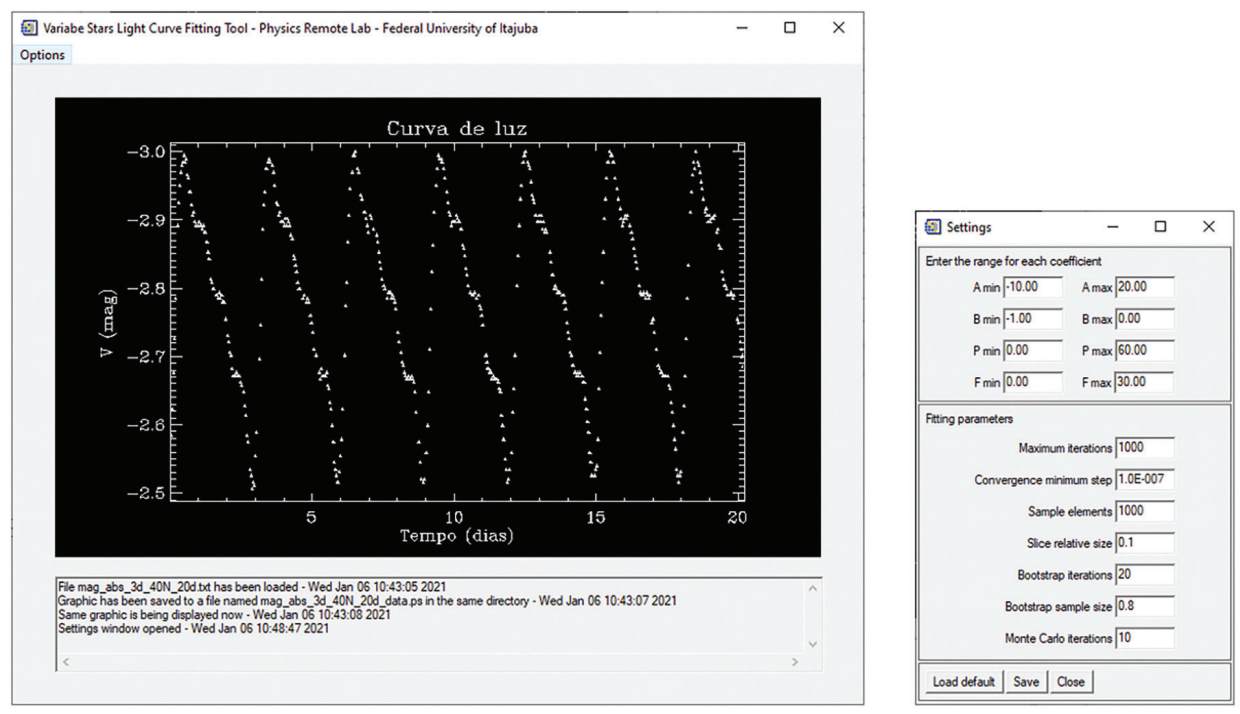

Figura 8: $\grave{A}$ esquerda: interface principal do programa FT. À direita: interface da opção settings, que permite ao usuário alterar as configurações do programa.

\section{Aquisição de Dados}

A coleta de dados pode ser algo simples, bastando acionar a lâmpada, selecionar as configurações desejadas e iniciar as medidas. O usuário pode definir o período de pulsação da fonte, quantas medidas serão realizadas por unidade de tempo e durante quanto tempo será feita a coleta de dados. Também é possível definir se as medidas serão fornecidas em termos de magnitudes absolutas ou relativas.

De modo sucinto, esse é o procedimento para a realização de uma única coleta de dados, todavia o experimento tem potencial para que seja realizada uma abordagem consideravelmente mais elaborada, explorando aspectos contextuais e epistemológicos. Vejamos mais detalhes dessa abordagem, a começar pela ferramenta de análise de dados que desenvolvemos especificamente com esse propósito.

\subsection{Ferramenta para análise de dados}

Foi desenvolvido um programa em IDL (Interactive Data Language) para auxiliar na análise dos dados, intitulado Variable Stars Light Curve Fitting Tool (a interface do programa é mostrada na Figura 8). Iremos nos referir a ele simplesmente por FT (de Fitting Tool). O programa pode ser baixado gratuitamente e pode ser executado sem que seja necessário que o usuário adquira uma licença do ambiente de desenvolvimento em IDL. Para isso, basta que seja instalada uma componente, a Virtual Machine, também gratuita. Todos esses recursos podem ser encontrados para download no site do labremoto ${ }^{9}$

Vejamos as principais funções do programa e os fundamentos da análise de dados feita por ele. O primeiro

\footnotetext{
9 https://labremoto.unifei.edu.br/materials/lightCurve/FT.zip
}

passo, logicamente, é a importação dos dados. Os arquivos gerados pelo "Curva de luz" podem ser importados através da opção Load no menu Options. Um gráfico é mostrado na interface imediatamente após a importação e uma cópia é salva no formato PS (Post Script) sempre no mesmo diretório do arquivo que foi selecionado. Examinando visualmente o gráfico, o usuário deve definir intervalos mais estritos para os coeficientes que se deseja determinar, através da janela settings. Isso contribui para que a análise seja mais rápida e os resultados, mais precisos. De acordo com a Equação (1):

a. O coeficiente $A$ corresponde aproximadamente à média entre os valores máximo e mínimo da magnitude. No exemplo da Figura 8, isso corresponde a algo em torno de $-2.75 \mathrm{mag}$, portanto um intervalo apropriado seria $[-2.65 ;-2.85]$;

b. O significado do coeficiente $B$ não é algo trivial, visto que esse parâmetro multiplica uma somatória de produtos envolvendo funções trigonométricas. É recomendável que esse intervalo permaneça como sugerido no programa, $[-1.0 ; 0.0]$;

c. O coeficiente $P$ equivale ao período, cuja estimativa pode ser facilmente obtida a partir do gráfico. No caso da Figura 8, algo em torno de 3.0 segundos. Portanto um intervalo adequado seria $[2.0 ; 4.0]$;

d. Por último, existe ainda um coeficiente $F$ que não está presente na Eq. (1). Trata-se de um artifício introduzido pelo programa para que seja possível realizar o ajuste. Esse coeficiente é uma espécie de ângulo de fase que controla o offset da curva na direção do eixo horizontal. Via de regra, seu valor máximo equivale ao valor do semiciclo e seu valor mínimo é zero. O intervalo apropriado, portanto, é $[0.0 ; 2.0]$. 
Com os intervalos definidos, o ajuste é realizado selecionando-se a opção Run no menu Options. O método empregado consiste em uma combinação de técnicas estatísticas paramétricas e, em alguns casos, iterativas, quais sejam o cross-entropy, bootstrapping e o método de Monte Carlo [38 40.

O primeiro passo executado pelo programa consiste em produzir as amostras iniciais, uma para cada coeficiente que será ajustado. Os elementos da amostra são determinados arbitrariamente segundo uma distribuição uniforme de probabilidades e com valores pertencentes ao intervalo que foi definido anteriormente. Como a ordem dos elementos é um fator relevante, vamos tratar as amostras como vetores em $\mathbb{R}^{s}$, sendo $s$ o tamanho da amostra. Dessa forma, $\boldsymbol{A}$ é o vetor cujas componentes $a_{0}, a_{1}, a_{2}, \ldots, a_{s-1}$ correspondem aos elementos da amostra gerada para o coeficiente $A$ :

$$
\boldsymbol{A}=a_{0} \widehat{\boldsymbol{u}}_{\mathbf{0}}+a_{1} \widehat{\boldsymbol{u}}_{\mathbf{1}}+a_{2} \widehat{\boldsymbol{u}}_{\mathbf{2}}+\cdots+a_{s-1} \widehat{\boldsymbol{u}}_{\boldsymbol{s}-\mathbf{1}}
$$

De modo análogo, definimos os vetores $\boldsymbol{B}, \boldsymbol{P}$ e $\boldsymbol{F}$ para os demais coeficientes.

No passo seguinte o programa obtém o valor $\delta_{i}^{2}$ para cada conjunto $\left\{a_{i}, b_{i}, p_{i}, f_{i}\right\}$, com $i=0,1,2 \ldots, s-1$. Esse valor representa a somatória dos quadrados das diferenças entre os valores empíricos $y_{j}$ obtidos com o experimento e os valores teóricos fornecidos pela Equação (1), para cada instante de tempo $t_{j}$. Na expressão seguinte, $Z$ é a quantidade de medidas disponíveis (quantidade de medidas coletadas através do experimento) e o parâmetro $k$ vale 4 .

$$
\delta_{i}^{2}=\sum_{j=0}^{Z-1}\left\{y_{j}-\left[a_{i}+b_{i} \sum_{n=1}^{k} \frac{1}{n} \operatorname{sen}\left(\frac{2 \pi n\left(t_{j}-f_{i}\right)}{p_{i}}\right)\right]\right\}^{2}
$$

Com base no resultado da equação, o programa seleciona as melhores soluções. Ou seja, as combinações $\left\{a_{i}, b_{i}, p_{i}, f_{i}\right\}$ que correspondem aos menores valores de $\delta_{i}^{2}$. Por definição, dez porcento de todas as combinações são selecionadas nessa fase, mas isso pode ser alterado na janela Settings. A partir desse subconjunto é realizado o processo de reamostragem. Para cada coeficiente, o processo consiste em:

a. determinar os limites do menor intervalo que contém os elementos do subconjunto;

b. produzir uma nova amostra obedecendo a uma distribuição normal de probabilidades cuja média está situada no centro do intervalo e o desvio padrão equivalente ao raio do intervalo.

O programa é recursivo a partir deste ponto. Os valores de $\delta_{i}^{2}$ são calculados novamente para a nova amostra, conforme a Equação (4). As melhores soluções são então selecionadas e realiza-se o processo de reamostragem outra vez. O processo todo é interrompido quando o critério de parada é satisfeito, o que ocorre quando a diferença entre os melhores valores de $\delta_{i}^{2}$ entre duas iterações consecutivas for inferior a $10^{-7}$ (configuração padrão). Ao final, tem-se a melhor solução $\{A, B, P, F\}$. $\mathrm{O}$ método descrito aqui, em que ocorre a amostragem e, depois, sucessivas reamostragens, constitui aquilo que chamamos de simulação de Monte Carlo e crossentropy. O primeiro termo deve-se ao caráter estatístico com que as amostras são produzidas, enquanto que o segundo refere-se à forma como as múltiplas amostras se interconectam durante a análise.

Por conta da natureza estatística do método, duas rodadas irão fornecer, muito provavelmente, valores ligeiramente diferentes para $\{A, B, P, F\}$, embora essa diferença esteja quase sempre dentro do intervalo de confiança. Eventualmente, todavia, é possível que o processo não apresente a convergência esperada e será necessário descartar os resultados neste caso. Para evitar que isso ocorra e conferir maior robustez ao processo, foi implementada uma técnica conhecida por bootstrapping. Basicamente, o processo cross-entropy é repetido várias vezes e, em cada rodada, uma fração dos dados originais é selecionada arbitrariamente e desprezada durante o ajuste. Segundo as definições padrão do programa, essa fração corresponde a $20 \%$ dos dados. A solução final $\{\bar{A}, \bar{B}, \bar{P}, \bar{F}\}$ equivale a média das soluções de todas as rodadas e os respectivos erros correspondem aos desvios padrão $\{\sigma A, \sigma B, \sigma P, \sigma F\}$. Valores discrepantes são removidos da análise durante o processo.

\subsection{A obtenção da relação período-luminosidade como elemento contextualizador}

A determinação da relação período-luminosidade para estrelas do tipo Cefeidas clássicas é feita a partir de um conjunto de estrelas para as quais a distância é conhecida, geralmente determinada por meio de outro método, como é o caso da paralaxe heliocêntrica [41, 42. Uma vez que a distância é conhecida, é possível determinar o valor da magnitude absoluta para essas estrelas através do módulo de distância (Equação (6)) e construir um gráfico que relaciona a magnitude absoluta com o período de pulsação. É possível, então, obter a relação períodoluminosidade através de um ajuste simples e o resultado é algo semelhante ao que é mostrado na Equação (5] [1].

$$
M_{V}=-\alpha \log P-\beta \quad(\operatorname{mag})
$$

De posse dessa equação, podemos obter magnitudes absolutas para estrelas cujas distâncias são desconhecidas, utilizando apenas o seu período de pulsação como parâmetro. O alcance deste método é muito superior ao da paralaxe heliocêntrica, permitindo o cálculo de distâncias para objetos mesmo fora da Galáxia. Assim foi como ocorreu historicamente e, portanto, uma abordagem que seja contextualizada dessa maneira possibilita a discussão de aspectos epistemológicos interessantes. Em particular, pode-se explorar o desenvolvimento e implicações dos trabalhos de Edwin P. Hubble no início do século $\mathrm{XX}$, os quais contribuíram expressivamente 
para o avanço do conhecimento em Astronomia Extragaláctica e em Cosmologia Observacional. Os estudantes têm, deste modo, a chance de compreenderem como o conhecimento da área foi construído, como evoluíram as ideias sobre o Universo neste período, em particular.

No caso do "Curva de luz", o primeiro passo na direção dessa abordagem consistiria na obtenção de uma relação período-luminosidade calibrada. Isso pode ser feito a partir de um conjunto de curvas de luz obtido em termos das magnitudes absolutas, as quais são fornecidas diretamente pelo experimento. Quando optamos por receber os dados em magnitudes absolutas, deve estar subentendido que as distâncias dos objetos são conhecidas pelo programa. Com auxílio do FT, podemos determinar os parâmetros dos ajustes das curvas de luz aos dados fornecidos pelo experimento. Constrói-se, então, um gráfico das magnitudes absolutas médias pelo logaritmo do período de pulsação e faz-se a determinação dos coeficientes da Equação (5) através de uma regressão linear. Isso conclui a primeira fase da abordagem: a obtenção de uma relação período-luminosidade calibrada.

$\mathrm{Na}$ segunda fase, os estudantes devem obter um conjunto de curvas de luz, desta vez em termos de magnitudes aparentes e realizar a determinação da distância para cada objeto desse conjunto. Primeiro, é feita a determinação do período de pulsação e da magnitude aparente média com auxílio do FT. Em seguida, utilizando a relação período-luminosidade calibrada da primeira fase, faz-se a determinação da magnitude absoluta da estrela
(Equação (5)). A distância é obtida a partir do módulo de distância (Equação (6)):

$$
m-M=5 \log d-5
$$

em que $m$ representa a magnitude aparente média, $M$ representa a magnitude absoluta, calculada com a Equação (5); e $d$ é a distância em parsecs. Como se trata de um experimento didático, o efeito da extinção interestelar não é considerado no cálculo da distância. Dessa forma, os objetos parecem estar mais distantes do que realmente estão, devido a um avermelhamento causado pelo meio. Mas essas discussões não pertencem ao escopo deste trabalho ou da atividade que está sendo proposta. Todavia, podem ser exploradas pelo docente.

\section{Análise dos dados e resultados}

Foram obtidas 20 curvas de luz com magnitudes absolutas. Para cada caso, foi utilizada uma amostragem de 30 medidas por unidade de tempo durante um intervalo de 30 "dias". Os períodos foram gerados aleatoriamente pelo programa e os coeficientes do ajuste foram obtidos com o FT.

Todos os ajustes foram realizados sob as mesmas condições: foram utilizadas amostras com 300 elementos, 10 iterações para o bootstrapping e 5 iterações para as simulações de Monte Carlo. Os demais parâmetros permaneceram com os valores padrão fornecidos pelo programa. A Tabela 1 contém os resultados.

Tabela 1: Resultados dos ajustes realizados com o FT para 20 curvas de luz fornecidas pelo experimento "Curva de luz" do labremoto*.

\begin{tabular}{|c|c|c|c|c|c|c|c|c|}
\hline & $\mathrm{M}_{\mathrm{V}}^{* *}(\mathrm{mag})$ & $\sigma$ (mag) & $\mathrm{P}$ (dias) & $\sigma$ (dias) & B (mag) & $\sigma$ (mag) & $\mathrm{F}$ (dias) & $\sigma($ dias $)$ \\
\hline 1 & -4.495 & 0.000 & 12.005 & 0.002 & -0.162 & 0.001 & 3.486 & 0.003 \\
\hline 2 & -4.134 & 0.001 & 9.052 & 0.001 & -0.161 & 0.002 & 6.000 & 0.003 \\
\hline 3 & -3.157 & 0.002 & 4.003 & 0.000 & -0.159 & 0.002 & 1.282 & 0.002 \\
\hline 4 & -3.835 & 0.001 & 7.006 & 0.002 & -0.160 & 0.001 & 1.775 & 0.001 \\
\hline 5 & -4.466 & 0.002 & 12.009 & 0.009 & -0.160 & 0.000 & 3.284 & 0.001 \\
\hline 6 & -5.369 & 0.000 & 24.759 & 0.030 & -0.162 & 0.001 & 16.977 & 0.002 \\
\hline 7 & -4.380 & 0.000 & 11.010 & 0.005 & -0.158 & 0.002 & 6.644 & 0.001 \\
\hline 8 & -4.583 & 0.005 & 12.192 & 0.007 & -0.140 & 0.004 & 0.000 & 0.016 \\
\hline 9 & -3.992 & 0.001 & 8.003 & 0.007 & -0.158 & 0.001 & 3.939 & 0.002 \\
\hline 10 & -4.339 & 0.041 & 10.977 & 0.036 & -0.154 & 0.007 & 6.992 & 1.356 \\
\hline 11 & -4.138 & 0.001 & 9.001 & 0.004 & -0.160 & 0.002 & 6.220 & 0.001 \\
\hline 12 & -4.464 & 0.001 & 12.005 & 0.008 & -0.159 & 0.001 & 5.461 & 0.002 \\
\hline 13 & -2.773 & 0.001 & 3.003 & 0.001 & -0.155 & 0.002 & 1.232 & 0.001 \\
\hline 14 & -3.116 & 0.001 & 4.004 & 0.001 & -0.152 & 0.001 & 1.511 & 0.002 \\
\hline 15 & -4.546 & 0.001 & 11.827 & 0.031 & -0.136 & 0.001 & 0.007 & 0.122 \\
\hline 16 & -4.239 & 0.000 & 10.013 & 0.005 & -0.155 & 0.002 & 1.743 & 0.002 \\
\hline 17 & -2.274 & 0.004 & 2.001 & 0.001 & -0.142 & 0.002 & 2.769 & 0.008 \\
\hline 18 & -4.457 & 0.003 & 13.154 & 0.061 & -0.128 & 0.002 & 8.000 & 0.149 \\
\hline 19 & -2.759 & 0.001 & 3.004 & 0.001 & -0.153 & 0.000 & 2.161 & 0.001 \\
\hline 20 & -3.384 & 0.001 & 5.009 & 0.002 & -0.154 & 0.001 & 2.114 & 0.000 \\
\hline
\end{tabular}




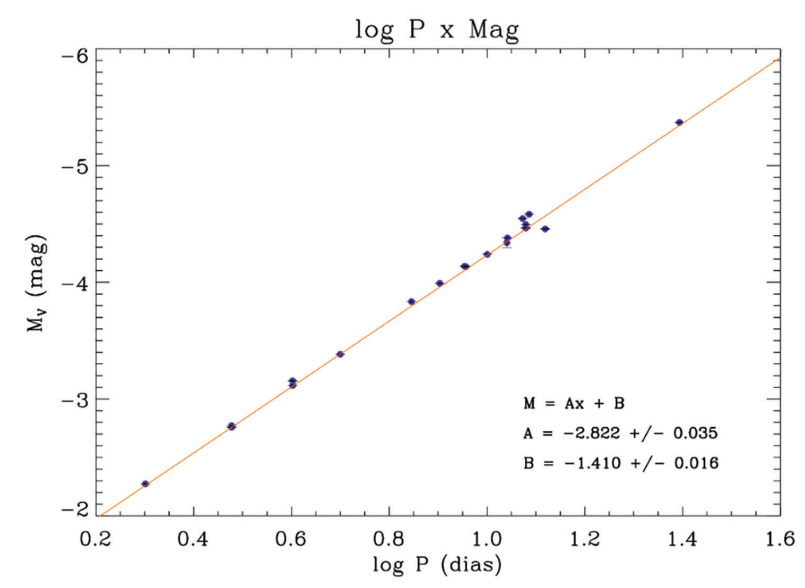

Figura 9: Gráfico das magnitudes absolutas médias pelo logaritmo do período de pulsação dos objetos da Tabela 1

A partir dos dados da Tabela 1 construímos o gráfico mostrado na Figura 9 O eixo vertical representa os valores das magnitudes absolutas médias $(\mathrm{V})$ e no eixo horizontal estão os valores do logaritmo do período de pulsação. Uma função linear foi ajustada aos dados utilizando o método $\chi$-quadrado. Os valores dos coeficientes são mostrados na Figura 9 e também na Equação (7).

A relação período-luminosidade calibrada é:

$$
M_{V}=-2.822 \log P-1.410 \quad(\text { mag })
$$

Agora é possível a determinação da distância de uma estrela com base no seu período de pulsação e sua magnitude aparente média. Ou seja, hipoteticamente, poderíamos agora realizar a determinação de distâncias para objetos cujas distâncias não podem ser determinadas por paralaxe heliocêntrica. Os estudantes podem obter uma curva de luz com o experimento, utilizando magnitudes aparentes desta vez, e determinar a distância do objeto, a qual é definida arbitrariamente pelo experimento e permanece incógnita para os usuários. A distância pode assumir qualquer valor entre $100 \mathrm{e}$ 10000 parsecs.

A título de ilustração, realizamos um ensaio experimental no qual obtivemos uma curva de luz em termos de magnitudes aparentes. Em seguida, foi feita a análise com o FT, da forma usual. O resultado do ajuste realizado pelo programa é mostrado na Figura 10. A magnitude aparente média encontrada foi de $(4.521 \pm$ 0.003) mag e o período de pulsação da estrela é de (6.000 \pm 0.002$)$ dias. Através da Equação (7) obtém-se o valor de $(-3.6 \pm 0.2)$ mag para a magnitude absoluta média do objeto em questão. Por fim, com auxílio da Equação 6 (módulo de distância), encontramos que a distância da estrela é de $(420 \pm 4)$ parsecs.

Para concluir a abordagem, o docente pode promover uma discussão sobre a localização dos objetos segundo as distâncias obtidas e implicações. Entre as questões que podem ser apresentadas, citamos: $\mathrm{O}$ objeto poderia estar próximo ao centro da Galáxia? Seria um objeto da

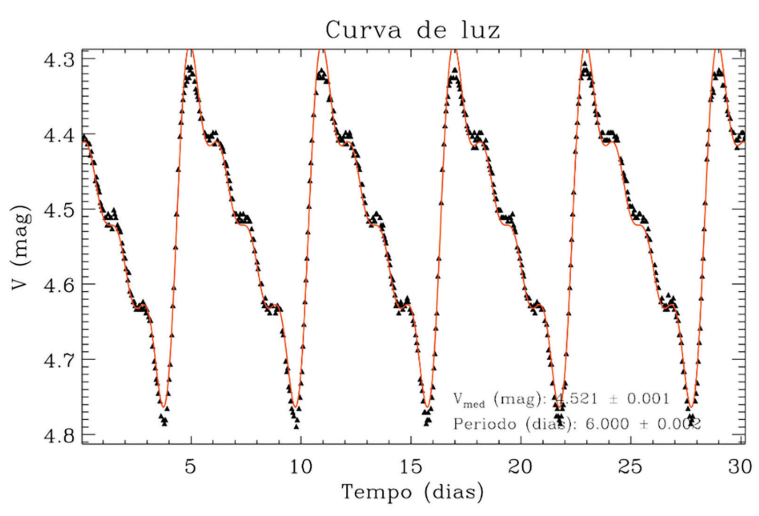

Figura 10: Resultado do ajuste realizado pelo FT para a curva de luz obtida em termos de magnitudes aparentes para um objeto com distância desconhecida.

vizinhança Solar? Poderia o objeto pertencer ao braço de Perseu? Ou talvez de Sagitário-Carina? O objeto encontra-se em nossa Galáxia? Entre outras questões. É importante que seja reservado um momento ao final da atividade para revisão dos passos, dos procedimentos e da sequência de eventos. O objetivo aqui é que a atividade seja colocada em perspectiva, contribuindo para que os estudantes enxerguem e compreendam os aspectos epistemológicos subjacentes à atividade.

\section{Considerações Finais}

Procuramos apresentar o experimento "Curva de luz" do labremoto, discutindo detalhes da sua construção através das várias áreas do seu desenvolvimento. Acreditamos que essas informações sejam relevantes tanto para que o leitor possa ter uma visão mais aprofundada do funcionamento, como para que certos aspectos da coleta e da análise de dados possam estar fundamentados nas características instrumentais do conjunto. Também buscamos descrever aqui o procedimento experimental, a coleta e análise dos dados. Mas não só isso. É importante trazer à atenção do leitor, uma vez mais, a proposta de ensino subjacente ao procedimento experimental, qual seja: uma abordagem investigativa na qual certos aspectos epistemológicos constituem parâmetros norteadores e que devem permear as discussões em todos os momentos da atividade. No que diz respeito à proposta ressalta-se, contudo, que este trabalho limitouse em apresentar apenas um arcabouço com as principais ideias, na expectativa de que isso possa demonstrar as potencialidades do "Curva de luz". Não foi o nosso intuito entrar em discussões mais aprofundadas sobre particularidades de natureza didática.

$\mathrm{O}$ experimento e a abordagem apresentados neste trabalho foram empregados na disciplina "Conceitos de Astronomia - AST929" do curso de Licenciatura em Física da Unifei, com alunos ingressantes. Apesar do fato de que esses estudantes tiveram pouco contato com as ferramentas matemáticas do Ensino Superior, 
a atividade pôde ser realizada sem prejuízo porque a análise estatística é feita por intermédio do programa FT, poupando os estudantes nessa fase do curso. Ao menos neste caso, é necessário estar atento para que seja mantido o foco nos aspectos mais conceituais, no estudo do método, no caráter histórico da atividade, entre outros. Contudo, desde que aplicadas as modificações adequadas, os mesmos experimento e abordagem podem ser utilizados novamente em outro momento do curso, tornando possível que os estudantes desvendem essa espécie de "caixa preta" e analisem de forma minuciosa o procedimento que é realizado dentro do programa.

Para concluirmos, acreditamos que seria interessante trazer o "experimento remoto" para o centro da discussão por um momento e reiterar certos pressupostos educacionais por trás deste recurso - e do labremoto como um todo. O primeiro ponto relevante é o fato de que os experimentos remotos não pretendem substituir os experimentos clássicos de bancada. Mas sim, devem ser utilizados preferencialmente em circunstâncias onde o experimento tradicional não é possível ou não é viável. O caso apresentado neste trabalho é um ótimo exemplo.

O fenômeno da variabilidade das estrelas do tipo Cefeida ocorre em uma escala de tempo que dificulta a realização de atividades didáticas de caráter mais prático. Além disso deve-se considerar fatores que normalmente constituem um empecilho à observação, como a poluição luminosa (principalmente nos grandes centros), o tempo e a infraestrutura para as aulas, segurança, as condições climáticas, o fato das observações só serem possíveis durante a noite, entre outros. Com o recurso da experimentação remota é possível ajustar a escala de tempo do fenômeno. Os estudantes coletam, em segundos, dados que levariam dias para serem coletados com observações. Além disso, não há interrupções. É como se estivéssemos observando o objeto a partir de um ponto fora da atmosfera terrestre. Outra vantagem consiste no fato de que os estudantes têm acesso ao aparato experimental de onde estiverem, bastando ter acesso à internet. Isso elimina a preocupação com infraestrutura e com as questões envolvendo segurança.

Como se trata de um experimento verdadeiro e não de uma simulação, podemos citar ainda algumas vantagens de cunho didático-pedagógico. Ao lidar com o experimento, os estudantes estarão coletando dados com instrumentos reais e sujeitos a flutuações estatísticas que existem normalmente nos experimentos. Frequentemente os estudantes precisam realizar a leitura de instrumentos - analógicos, na maioria das vezes - através das imagens mostradas pelas câmeras. Nesse processo têm a oportunidade de colocar em prática conceitos como precisão, exatidão, faixa de operação, interpolação e erro instrumental. Ao coletarem dados, precisam levar em consideração as características dos instrumentos utilizados, seu limite de operação, fatores que podem introduzir erros nas medidas e influenciar o comportamento dos dados, de uma forma geral. Essa análise é necessária para que possam determinar a confiabilidade dos resultados. Ou seja, para além daquilo que se deseja investigar, é possível refletir sobre o método e estudar o procedimento experimental que se utiliza.

Talvez a questão mais interessante, todavia, seja o fato de que, com um experimento, é possível observar algo que nenhum outro tenha observado. Isso permite levantar ideias novas, hipóteses e, quiçá, até um novo conhecimento.

\section{Referências}

[1] B.W. Carrol e D.A. Ostlie, An introduction to modern astrophysics (Pearson Addison Wesley, San Francisco, 2007), $2^{\mathrm{a}}$ ed.

[2] F. Wang e M.J. Hannafin, Educational technology research and development 53, 5 (2005)

[3] C. Chia-Chen e L. Pei-Hsuan, Interactive Learning Environments 24, 644 (2016)

[4] A.K. Mohammed, H.M. El Zoghby e M.M. Elmesalawy, Remote Controlled Laboratory Experiments for Engineering Education in the Post-COVID-19 Era: Concept and Example (Institute of Electrical and Electronics Engineers, Piscataway, 2020).

[5] T.C. Roque, M.L. Benedet e J.S. Medeiros, Brazilian Journal of Development 5, 23708 (2019).

[6] J.B. Silva, S.M.S. Bilessimo, G.R. Scheffer e I.N. Silva, EaD em Foco, 10, e810 (2020).

[7] S.A.A. Scheffer, Sequências didáticas investigativas com o uso de laboratórios remotos e virtuais: proposta para aulas de física no ensino médio. Dissertação de Mestrado, Universidade Federal de Santa Catarina, Araranguá (2020).

[8] R.E. Romero, A.F. Stoessel e A. Rocha, Revista de enseñanza de la física 32, 75 (2020).

[9] D. Herrero-Villareal, C. Arguedas-Matarrita e E. Gutiérrez-Soto, Revista de Enseñanza de la Física 32, 181 (2020).

[10] E.L. Martínez Piñeiro, Revista Mexicana de Bachillerato a Distancia 13, 1 (2021).

[11] T.C. Caetano, Journal of Education 7, 92 (2019).

[12] J.S. Sandoval e L.C. Cudmani, Revista de Enseñanza de la Física 5, 10 (1992).

[13] D. Delizoicov e J.A. Angotti, Metodologia no ensino de ciências (Cortez, São Paulo, 1994), $2^{\text {a }}$ ed.

[14] D. Hodson, Journal of Curriculum Studies 28, 92 (1996).

[15] S.M. Arruda, C.E. Laburú, em: Questões atuais no ensino de ciências, editado por R. Nardi (Escrituras, São Paulo, 1998), p. 53.

[16] M. Giordan, Química nova na escola 10, 43 (1999).

[17] J.P. Alves, Caderno brasileiro de ensino de Física 17, $174(2000)$.

[18] A.T. Borges, Caderno Brasileiro de Ensino de Física 19, 291 (2002).

[19] M.S.T. Araújo e M.L.V.S. Abib, Revista Brasileira de Ensino de Física 25, 176 (2003).

[20] M. Seré, S.M. Coelho, A.D. Nunes, Caderno Brasileiro de Ensino de Física 20, 30 (2003). 
[21] S.C. Binsfeld e M.A. Auth, em: Encontro Nacional de Pesquisa em Educação em Ciências (Campinas, 2011).

[22] E. Amaral, B.G. Avila e L.M.R. Tarouco, em: Brazilian Symposium on Computers in Education - Simpósio Brasileiro de Informática na Educação-SBIE (Brasília, 2012).

[23] A.T. Santos, P. Tamiasso-Martinhon, Â.S. Rocha, C. Sousa e S.M.L. Agostinho, Scientia Naturalis 1, 209 (2019).

[24] F.S. Wesendonk, E.A. Terrazzan, ENCITEC - Ensino de Ciências e Tecnologia em Revista 10, 39 (2020).

[25] R. Axt, in: Tópicos em Ensino de Ciências, editado por M.A. Moreira, R. Axt (Sagra, Porto Alegre, 1991).

[26] B.G. Kanbach, C.E. Laburú e O.H.M. Silva, em: XVI Simpósio Nacional de Ensino de Física (Rio de Janeiro, 2005).

[27] M.C.S. Zancul, em: Quanta Ciência há no Ensino de Ciências, editado por A.C. Pavão e D. Freitas (Edufscar, São Carlos, 2008).

[28] L.B.C. Ramos e P.R.S. Rosa, Investigações em Ensino de Ciências 13, 299 (2008).

[29] F.L.A. Pena e A. Ribeiro Filho, Revista Brasileira de Pesquisa em Educação em Ciências 9, 1971 (2009).

[30] M.L.F. Andrade e V.G. Massabni, Ciência \& Educação 17, 835 (2011).

[31] L.B. Zanon e R.I.M. Uhmann, em: XVI ENEQ/X EDUQUI (Salvador, 2013).

[32] Instituto Nacional de Estudos e Pesquisas Educacionais Anísio Teixeira. Censo da Educação Básica 2020: notas estatísticas (INEP, Brasília, 2021).

[33] M. Pedaste, M. Mäeots, L.A. Siiman, T. Jong, S. van Riesen, E.T. Kamp, C.C. Manoli, Z.C. Zacharia e E. Tsourlidaki, Educational research review 14, 47 (2015).

[34] D.C. Ernst, A. Hodge e S. Yoshinobu, Notices of the AMS 64, 570 (2017).

[35] N.R. Tanvir, M.A. Hendry, A. Watkins, S.M. Kanbur, L.N. Berdnikov e C.C. Ngeow, Monthly Notices of the Royal Astronomical Society 363, 749 (2005).

[36] A. Bhardwaj, S. Kanbur, M. Marconi, H. Singh, M. Rejkuba e C.C. Ngeow, Proceedings of the International Astronomical Union 14, 287 (2017).

[37] F. Ragosta, M. Marconi, R. Molinaro, V. Ripepi, M.R.L. Cioni, M.I. Moretti, M.A.T. Groenewegen, S. Choudhury, R. Grijs, J.T. van Loon et al., Monthly Notices of the Royal Astronomical Society 490, 4975 (2019).

[38] B. Efron e R.J. Tibshirani, An introduction to the bootstrap (CRC Press, Boca Raton, 1994).

[39] B. Efron, Journal of the American Statistical Association 95, 1293 (2000).

[40] B. Efron, Statistical science 18, 135 (2003).

[41] M.J. Pryor, Journal of the Royal Astronomical Society of Canada 66, 53 (1972).

[42] B. Sesar, M. Fouesneau, A.M. Proce-Whelan, C.A. Bailer-Jones, A. Gould, H. W. Rix, The Astrophysical Journal 838, 107 (2017). 